\title{
The new Editor: Dr George Misiewicz
}

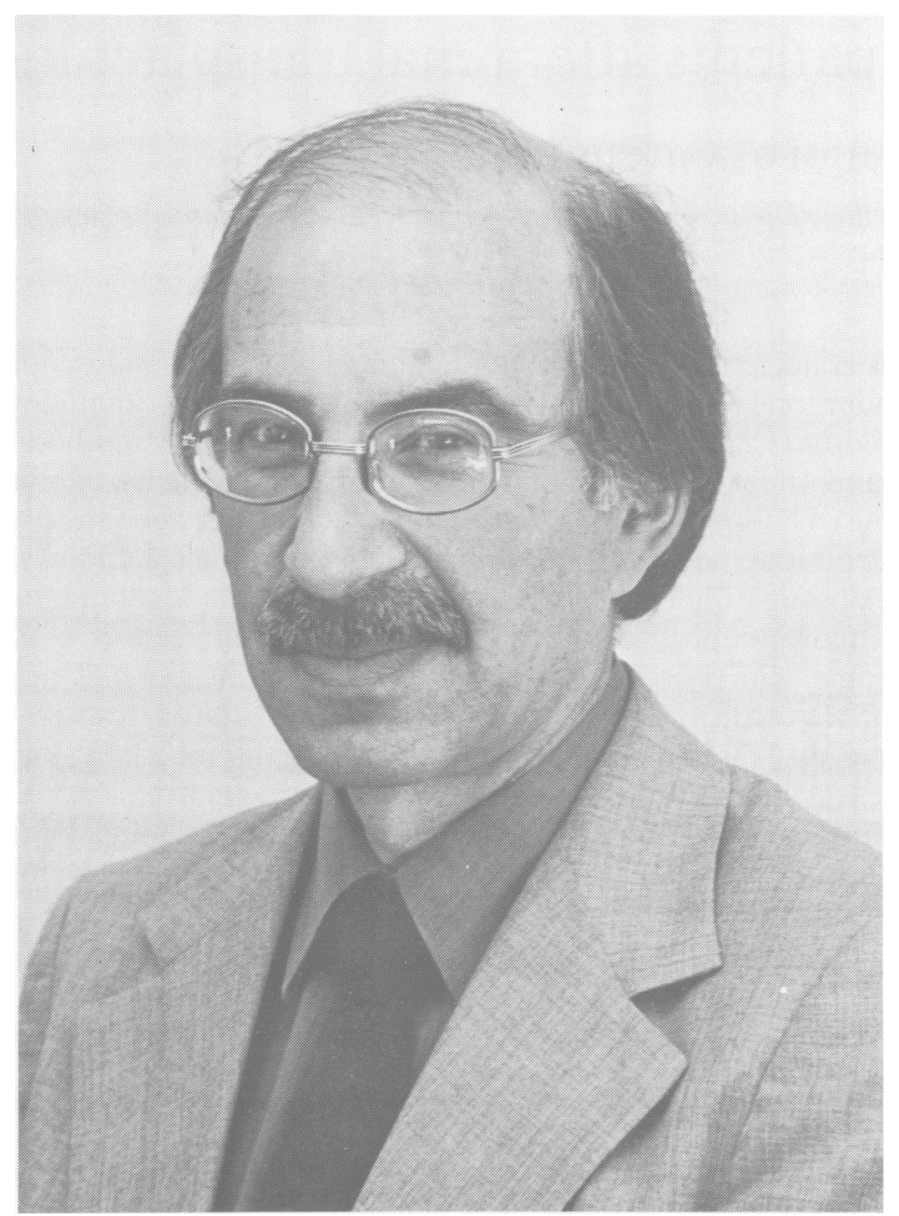

The new editor takes over on 1 October 1981. Dr J J Misiewicz graduated in medicine from St Bartholomew's Hospital in 1956, having previously taken an honours BSc degree in the University of London. He was for many years a member of the Medical Research Council's Gastroenterology Research Unit at the Central Middlesex Hospital where he worked closely with the 'founding father' of Gut, Sir Francis Avery Jones. He is currently consultant physician at the Central Middlesex Hospital and a member of the external staff of the Medical Research Council.

Dr Misiewicz has made major contributions to our knowledge of gastroenterology; in particular, he was closely involved with the development, in association with Sir James Black, FRS, of the use of cimetidine for the treatment of duodenal ulcer. Serving as a member of the editorial board of Gut since 1974, he has during the past five years been responsible for the book reviews and notes in the news section.

$\mathrm{He}$ is a man of wide cultural interests and a joy and delight to his many friends in gastroenterology who wish him well in his new task. 